\title{
Transaction
}

\section{Intermediate States of Aqueous Solution of Agarose on Quasi-Static Cooling}

\author{
Seiichiro Yokokawa ${ }^{* 1}$ and Yoshiharu Nishiyama ${ }^{* 2}$
}

\author{
${ }^{* 1}$ Department of Biomaterials Science, Graduate School of Agricultural and Life Sciences, \\ The University of Tokyo, Bunkyo-ku, Tokyo, 113-8657, Japan \\ ${ }^{* 2}$ Centre de Recherches sur les Macromolécules Végétables (CERMAV, ICMG-CNRS), \\ BP 53, F38041 Grenoble Cedex 9, France, affiliated with Université Joseph Fourier
}

\begin{abstract}
We studied gelation behavior of aqueous solution of agarose (1.0wt\%) using light scattering and rheological measurement. Aqueous solution of agarose (1.0wt \%) showed a stepwise structural evolution via a series of stages when it was cooling very slowly from the solutions. The stage includes: i) Homogeneous solution at above $62^{\circ} \mathrm{C}$; ii) inhomogeneous transition stage at $61^{\circ} \mathrm{C}-51^{\circ} \mathrm{C}$, where the mean scattering intensity steadily increased with temperature drop; iii) homogeneous intermediate state at $50^{\circ} \mathrm{C}-38^{\circ} \mathrm{C}$, where scattering intensity stays constant; iv) second transition stage at $37^{\circ} \mathrm{C}-34^{\circ} \mathrm{C}$, where scattering intensity rised steeply; and v) typical gel state at below $34^{\circ} \mathrm{C}$. All states below $62^{\circ} \mathrm{C}$ showed hysteresis in that the return to solution required reheating to above $93^{\circ} \mathrm{C}$. Because the loss modulus G" was close to the storage modulus $G^{\prime}$ in the state iii), the phenomenon at this temperature range seems to be a weak gelation. Large fluctuations of scattering intensity in time and/or space observed in the stages ii) and v) indicate the presense of mobile or frozen-in inhomogeneities.
\end{abstract}

(Received 15 December, 2004; Accepted 2 February, 2005 )

\section{Introduction}

Agarose, a neutral cell-wall polysaccharide extracted from a class of red algae, consists mainly of 1,3-linked agarobiose (D-galactopyranosyl $(1 \rightarrow 4)-\mathrm{O}-3,6$ - anhydroalpha-L-galactopyranosyl) [1]. The aqueous agarose system forms a thermoreversible gel with a typical gelation point around $35^{\circ} \mathrm{C}$ and, meltiong point of above $90^{\circ} \mathrm{C}$. Molecular mechanism of association in agarose gel has been studied by using X-ray diffraction [2,3], optical rotation [2,4-6] and molecular modeling [7,8], and the gelation is generally considered to involve a coil-helix transition and lateral aggregation of helices [9,10]. Double helix formation was proposed in the late 1960s [11] and has been accepted by many researchers, but some have proposed a single helical model [12]. Formation of a single helix was checked by X-ray diffraction [3] and from ab-initio calculations [7,8]. Since the helices of agarose molecules in the gel remains poorly crystalline and does not allow the crystallographic analisis. In the course of gelation, the helix is believed to aggregate to form fibrillar bundles observed by cryo-electron microscopy [13]. One of the proof of the fibrillar bundles is the large pore size that makes it an excellent material for DNA electrophoresis.

The process preceding gelation of aqueous systems has also been studied mainly by differential scanning calorimetry [14], light scattering [15-18] and rheological measurements [19-21]. Based on the phenomena observed by temporal evolution of scattering intensities after quench either at high temperature or low concentration [14, 16-18], some authors interpreted the process as a spinodal decomposition. Thus, the higher-order structure and physical properties of agarose gel depend strongly on the thermal history. While Aymard et al. [20] demonstrated certain structure formation in very slow cooling or elongated curing at around $40^{\circ} \mathrm{C}$, quantitative information on the influence of cooling rate and the temperature range for this process has not been reported. In this study, we examined the structural evolution of a $1.0 \mathrm{wt} \%$ aqueous agarose solution by a stepwise cooling with a rate less than $0.008^{\circ} \mathrm{C} / \mathrm{min}$, and two distinct atages were obserbed before final gelation.

\section{Experimental}

\subsection{Sample preparation}

Agarose Type I-A (Sigma, low EEO, Lot No. 232-731-8 ) was dispersed in distilled water and allowed to swell for more than 12 hours. Then the mixture was heated at $100^{\circ} \mathrm{C}$ with stirring for 1 hour to dissolve completely. Weight average molecular weight of agarose was determined by light scattering (Zimm plot [23]) as $\mathrm{M}_{\mathrm{w}}=1.64 \times 10^{5}$, with $\mathrm{z}$-average radius of gyration, $\mathrm{R}_{\mathrm{g}, \mathrm{Z}}=$ 
$68.3 \mathrm{~nm}$, and second virial coefficient, $\mathrm{A}_{2}=4.31 \times 10^{-4} \mathrm{ml}$ • $\mathrm{mol} / \mathrm{g}^{2}$.

\subsection{Light scattering measurement}

Light scattering experiments was carried out on Authorizer $4700 \mathrm{C}$ system (Malvern) with $50 \mathrm{~mW} \mathrm{He}-\mathrm{Ne}$ laser (Wavelength, $\lambda=633 \mathrm{~nm}$ ). The sample cell was inserted in a chamber filled with distilled water, which was thermostated within $\pm 0.1^{\circ} \mathrm{C}$. The hot agarose solution was quickly injected to the cell through a $0.45 \mu \mathrm{m}$ membrane filter. The cell was reheated to $100^{\circ} \mathrm{C}$ for removing influence of temperature lowering during manipulation.

Position dependence of scattering intensity was examined at $\theta=90^{\circ}$ (scattering vector, $q=4 \pi \mathrm{n}_{0} \sin (\theta / 2) \lambda^{-1}=0.0187$ $\mathrm{nm}^{-1} \cdot \mathrm{n}_{0}$ is the refractive index of the solvent.). Sample position was changed arbitrarily by rotating the cell, and data for 100 points were recorded. Angle dependence of scattering intensity was measured for $\theta=30-150^{\circ}$ $\left(\mathrm{q}=0.00683-0.0255 \mathrm{~nm}^{-1}\right)$. Measurements were carried out by stabilizing the sample for $120 \mathrm{~min}$ after each $1^{\circ} \mathrm{C}$ temperature drop from $65^{\circ} \mathrm{C}$ to $25^{\circ} \mathrm{C}$.

\subsection{Rheological measurement}

Rheosol-G 5000 (UBM) was used for the measurement. A parallel plate geometry of $25 \mathrm{~mm}$ wide was used. The hot solution (above $80^{\circ} \mathrm{C}$ ) of $1.0 \mathrm{wt} \%$ agarose was supplied to the geometry, followed by sealing with silicone oil for preventing evaporation of water. The sample was reheated to $95^{\circ} \mathrm{C}$ for avoiding influence of temperature drop during transfer, and then cooled to $65^{\circ} \mathrm{C}$ with cooling rate of $20^{\circ} \mathrm{C} / \mathrm{min}$. Storage and loss moduli, G' and G', were measured at $1.0 \mathrm{~Hz}(6.2 \mathrm{rad} / \mathrm{s})$, with $0.5 \%$ strain for $0.1^{\circ} \mathrm{C} / \mathrm{min}$ or $1.0^{\circ} \mathrm{C} / \mathrm{min}$ cooling from $65^{\circ} \mathrm{C}$ to $25^{\circ} \mathrm{C}$. For $0.1^{\circ} \mathrm{C} / \mathrm{min}$ cooling, the frequency dependence was also measured for $0.01-10 \mathrm{~Hz}$.

\section{Result and discussion}

Fig. 1 shows the change in scattering intensity for $1.0 \mathrm{wt} \%$ agarose for cooling from $65^{\circ} \mathrm{C}$ to $25^{\circ} \mathrm{C}$, with 120 min stabilization after each $1^{\circ} \mathrm{C}$ temperature drop. For the conditions causing position dependent fluctuation in scattering intensity (see below), the plotted value is the average of 100 measurement. Fig. 2 shows the position dependence of scattering intensity for selected temperatures. Based on these results, the state of the system is classified as five temperature ranges:

i) Hot solution, above $62^{\circ} \mathrm{C}$ : Scattering intensity takes a low and constant value, indicating that agarose is in molecularly dispersed state.

ii) First transition range, $62^{\circ} \mathrm{C}-50^{\circ} \mathrm{C}$ : Scattering intensity starts to rise, showing time and position dependent fluctuation between the minimum and maximum values (see Fig. 2(b)). The minimum is slightly higher than the value for hot solution; the maximum is about five times as much as that of the minimum value. While the minimum and maximum values are constant in this temperature range, the averaged value increases exponentially with temperature drop.

iii) Intermediate state, $50^{\circ} \mathrm{C}-38^{\circ} \mathrm{C}$ : Scattering intensity is constant at the maximum value in ii), and shows no time- or position dependence.

iv) Second transition range, $38^{\circ} \mathrm{C}-34^{\circ} \mathrm{C}$ : Scattering intensity rises steeply, reaching to approximately 100 times of that in iii).

v) Final gel: Scattering intensity becomes constant at a high level. It is constant as the fixed position, but shows spatial fluctuation as shown in Fig. 2(d).

The most remarkable feature revealed here is the occurrence of the first transition state, ii), and the intermediate state, iii). Separate examination of the sample in a test tube at $55^{\circ} \mathrm{C}$ and $45^{\circ} \mathrm{C}$ with the same thermal history showed that the sample was still fluid at $55^{\circ} \mathrm{C}$, and became gel-like at $45^{\circ} \mathrm{C}$. The sample at $45^{\circ} \mathrm{C}$ retained the shape against tumbling or moderate shaking, but disintegrated by vigorous shaking. A related feature is the occurrence of time-dependent fluctuation of scattering intensity in ii) (Fig. 2(b)), and its disappearance in iii) (Fig. 2(c)). Since the sample is fluid at $55^{\circ} \mathrm{C}$, the time-dependent fluctuation seems to be caused by random motion of minute clusters formed by association of agarose molecule. The increase in the averaged scattering intensity with cooling possibly reflects an increase in the population and/or the size of the clusters. The disappearance of fluctuation in iii),

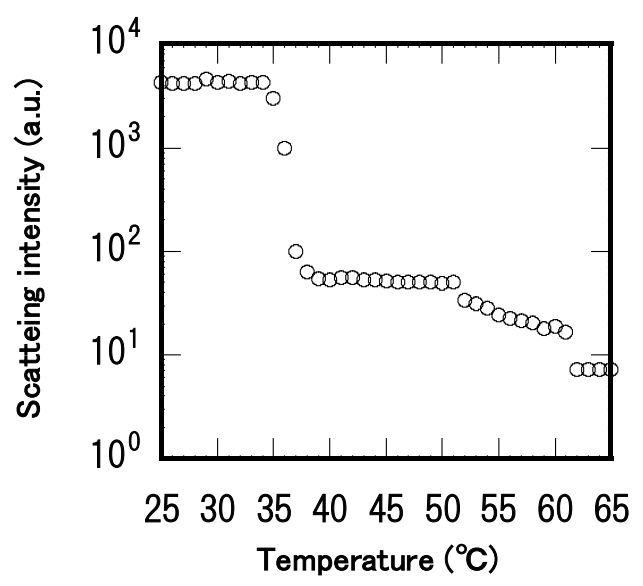

Fig. 1 Temperature dependence of scattering intensity of an $1.0 \mathrm{wt} \%$ agarose system with stabilization time of $120 \mathrm{~min}$ for $1^{\circ} \mathrm{C}$ drop each. 


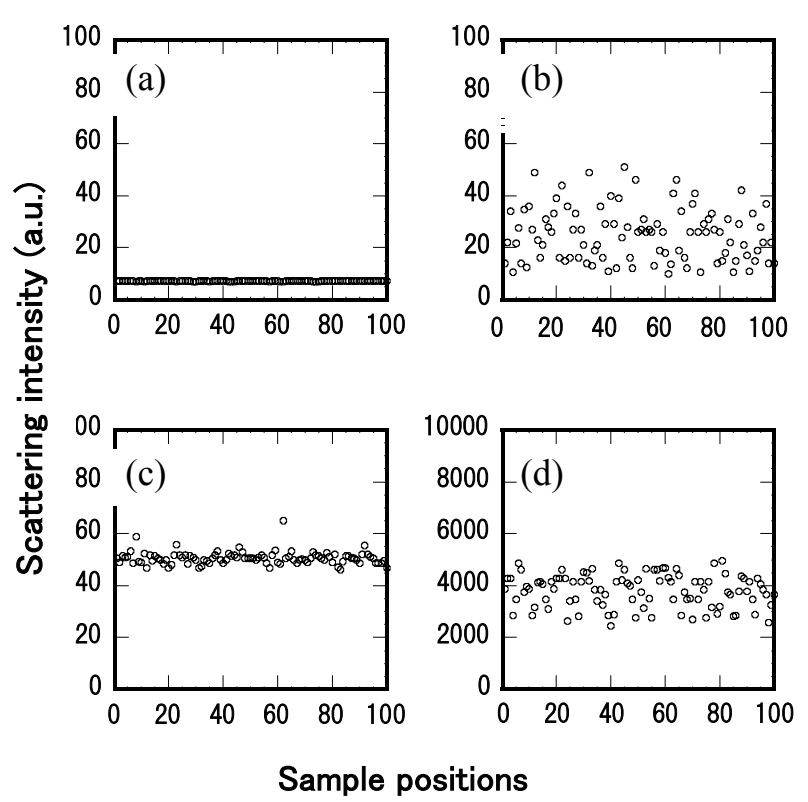

Fig. 2 Position dependence of scattering intensity of $1.0 \%$ agarose system at various temperatures. (a) $65^{\circ} \mathrm{C}$, (b) $55^{\circ} \mathrm{C},(\mathrm{c}) 45^{\circ} \mathrm{C}$ and (d) $30^{\circ} \mathrm{C}$.

both in time and position, may have resulted from immobilization of the clusters that filled the space through their growth. This state is gel-like as described above, but is different from the final gel in the absence of positional fluctuation. The positional fluctuation observed for the final gel (Fig. 2(d)) is related to the so-called laser speckles, i.e. the irregular interference pattern, which is observed for wide variety of gels and interpreted to reflect inhomogeneity in the network structure [24,25].

Fig. 3 shows the change in storage and loss moduli of $1.0 \mathrm{wt} \%$ agarose during the fast cooling $\left(1.0^{\circ} \mathrm{C} / \mathrm{min}\right)$ and the slow cooling $\left(0.1^{\circ} \mathrm{C} / \mathrm{min}\right)$. The fast cooling brought about an one-step transition between $40^{\circ} \mathrm{C}$ and $30^{\circ} \mathrm{C}$, with $\mathrm{G}^{\prime}$ exceeding $\mathrm{G}^{\prime \prime}$ at approximately $36^{\circ} \mathrm{C}$. This is typical behavior in sol-gel transition. In the slow cooling, on the other hand, behavior of G', is the same that as in the fast cooling, but that of $\mathrm{G}^{\prime}$ is significantly different; $G$ ' starts to rise at around $60^{\circ} \mathrm{C}$, reaches nearly a constant level close to $\mathrm{G}^{\prime \prime}$ at $50^{\circ} \mathrm{C}$, rises again from approx. $38^{\circ} \mathrm{C}$, and then converges to the curve in fast cooling. In the range of $\mathrm{G}^{\prime}=\mathrm{G}^{\prime \prime}, \mathrm{G}^{\prime}$ and $\mathrm{G}^{\prime \prime}$ did not show frequency dependence. In this region, since $G^{\prime}(\omega)$ is $G^{\prime \prime}(\omega)$, this state is a real gel [26].Similarly final gel did not show frequency dependence.

Based on these features in rheology, the state of $1.0 \%$ agarose at $50^{\circ} \mathrm{C}-40^{\circ} \mathrm{C}$ already forms an infinite network, but with weak molecular association. In fact both $\mathrm{G}^{\prime}$ and $\mathrm{G}$ ', are at least three orders of magnitude lower than at

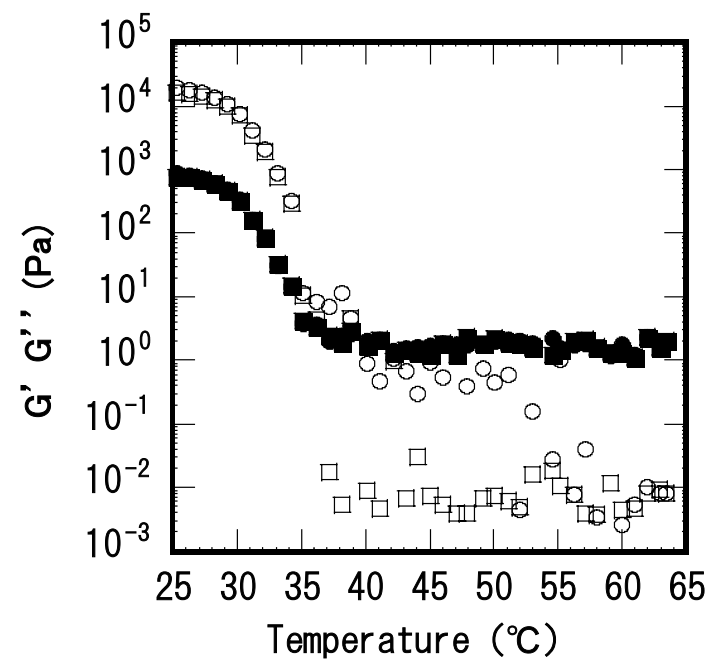

Fig. 3 Temperature dependence of storage modulus G' and loss modulus G" during the cooling process for $1 \mathrm{wt} \%$ agarose aqueous solution. $\gamma=0.5 \%$, $\mathrm{f}=1 \mathrm{~Hz}(\omega=6.2 \mathrm{rad} / \mathrm{s})$, and $25 \mathrm{~mm}$ parallel disk geometry. $\bigcirc:, 0.1{ }^{\circ} \mathrm{C} / \mathrm{min} ; \quad 0.1{ }^{\circ} \mathrm{C} / \mathrm{min}$; $\square: \mathrm{G}^{\prime}, 1.0^{\circ} \mathrm{C} / \mathrm{min} ; \mathbf{\square}: \mathrm{G}^{\prime}, 1.0^{\circ} \mathrm{C} / \mathrm{min}$.

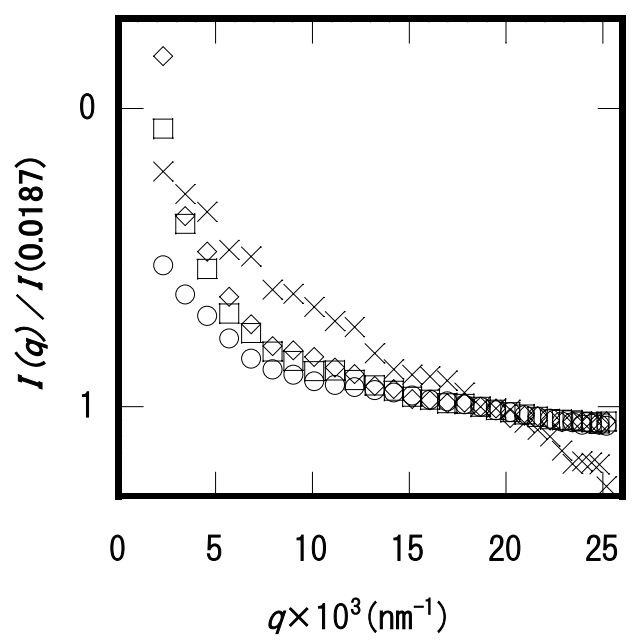

Fig. 4 Scattering vector dependence of scattering intensity for selected temperatures reached by slow cooling. Scattering intensity is normalized to the value at $q=0.0187 \mathrm{~nm}^{-1}\left(\theta=90^{\circ}\right)$. $\bigcirc: 65^{\circ} \mathrm{C} ; \square: 60^{\circ} \mathrm{C} ; \diamond: 45^{\circ} \mathrm{C}, \times: 30^{\circ} \mathrm{C}$.

conventional gel state below $30^{\circ} \mathrm{C}$. Aymard et al. [20] measured $\mathrm{G}^{\prime}$ at similar conditions but did not show this behavior probably because their instrument was not sensitive enough to detect the these orders of magnitude lower $\mathrm{G}^{\prime}$ mentioned above. Though the cooling rate in our rhological measurements was not as low as those in light 
scattering measurements due to instrumental limitation, a good correspondence is observed between Figs. 1 and 3 .

Fig. 4 shows the scattering vector dependence of relative scattering intensity (each normalized to the value at $q$ $\left.=0.0187 \mathrm{~nm}^{-1}\right)$ at selected temperatures reached by slow cooling ( more than $120 \mathrm{~min}$ per $1^{\circ} \mathrm{C}$ drop). Although we can check unusually larger scattering intensity of small $\mathrm{q}$ region at high temperature from this figure, this disappears below $35^{\circ} \mathrm{C}$. Fig. 5 shows $q^{2}$ vs $I(q)^{-1}$ plot that converted to the data in Fig. 4. Since plots in Fig.5 showed linear relation between $q^{2}$ and $I(q)^{-1}$ in small $q$ range, the correlation length for the range may be calculated by the

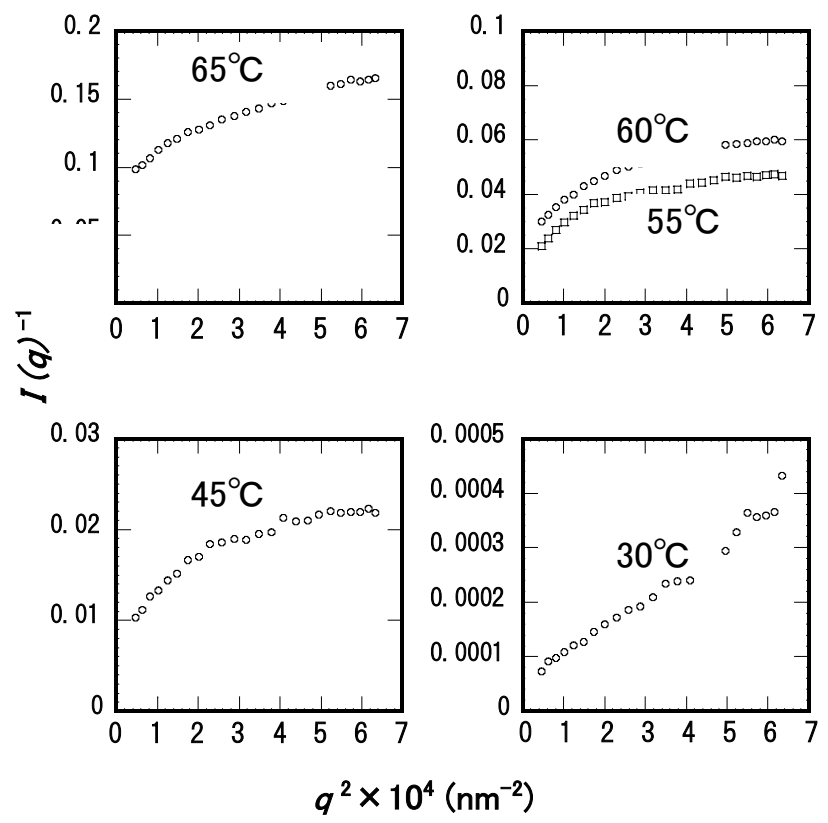

Fig. 5 Variations of $q^{2}$ vs $I(q)^{-1}$ at selected temperatures.

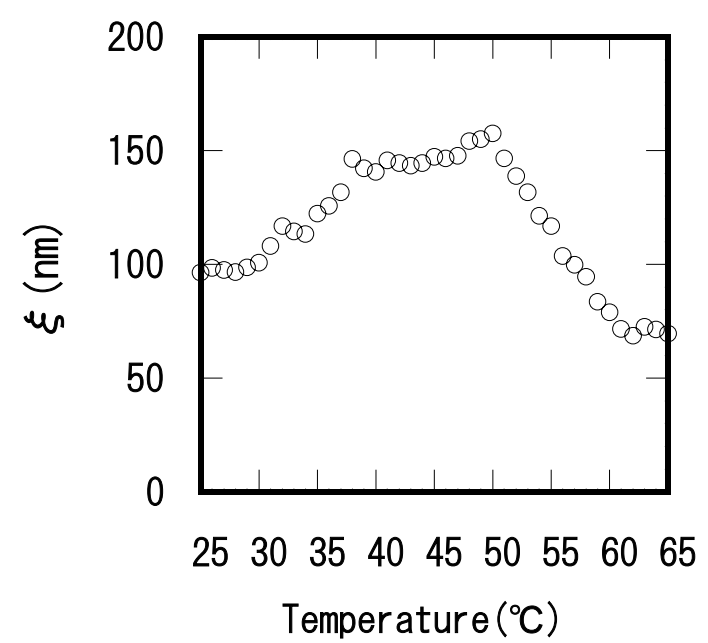

Fig. 6 Change in correlation length $\xi$ on the slow cooling calculated by Ornstein-Zernike equation from angle dependence of scattering intensity.
Ornstein-Zernike equation[27],

$$
I(q)=I(0) /\left[1+\xi^{2} q^{2}\right]
$$

where $I(q)$ is the scattering intensity for scattering vector $q$ and correlation length $\xi$. We obtain the temperature dependence of $\xi$ from the data in Fig. 6. This graph also shows certain correspondence with Figs. 1 and 3. Namely, $\xi$ remains constant at $72 \mathrm{~nm}$ in a hot solution until temperature drops to $61^{\circ} \mathrm{C}$; rises linearly to $150 \mathrm{~nm}$ at $61^{\circ} \mathrm{C}-50^{\circ} \mathrm{C}$, corresponding to the first transition; nearly constant at $50^{\circ} \mathrm{C}-38^{\circ} \mathrm{C}$ corresponding to the intermediate state; decreases to $100 \mathrm{~nm}$ at between $38^{\circ} \mathrm{C}$ and $30^{\circ} \mathrm{C}$, corresponding to the second transition; and then becomes constant at $100 \mathrm{~nm}$ for the final gel.

The $\xi$ of $72 \mathrm{~nm}$ in the hot solution is a measure of the average intermolecular distance at this concentration. The increase in $\xi$ at $61^{\circ} \mathrm{C}-50^{\circ} \mathrm{C}$ indicates the formation and gradual growth of certain association of agarose molecules that leads to coarsening of the system. The radius of gyration of agarose in water is known to decrease with decreasing temperature [16], and decreasing temperature also favours molecular association. The $\xi$ of $150 \mathrm{~nm}$ at $50^{\circ} \mathrm{C}-40^{\circ} \mathrm{C}$ can be interpreted as the network segment size [28] in the intermediate state. The segment size then decreases via the second transition to $100 \mathrm{~nm}$, that of the final gel. This last transition might be accompanied by conformational transition of agarose leading to tighter association.

Aymard et al. [20] reported observations that indicate certain structure formation in $2 \%$ aqueous agarose

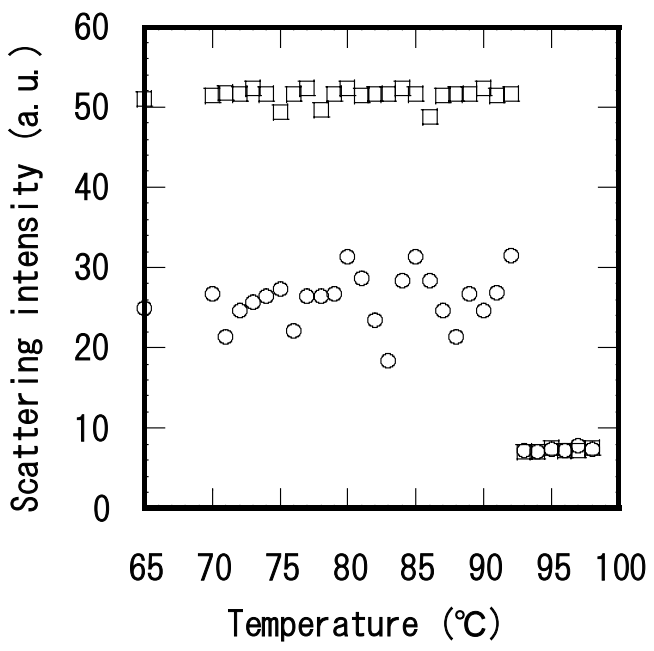

Fig. 7 Scattering intensity of $1.0 \%$ agarose reheated from $55^{\circ} \mathrm{C}(\circ)$ or $45^{\circ} \mathrm{C}(\square)$ reached by the slow cooling. 
solutions at above the gel point. They showed that the gel formed after curing at $35^{\circ} \mathrm{C}-45^{\circ} \mathrm{C}$ for several hours to several weeks had different microscopic morphologies and mechanical properties from those of ordinary gels. While they did not determine the temperature range for the curing to cause such differences, our observation showed that the temperature range for the "pre-gel" association is approximately $61^{\circ} \mathrm{C}-40^{\circ} \mathrm{C}$, which is further resolved into the "first transition" and the "intermediate" state.

To study reversibility of these high temperature processes, we measured light scattering of the sample reheated from $55^{\circ} \mathrm{C}$ (first transition range) and $45^{\circ} \mathrm{C}$ (intermediate state) to above $65^{\circ} \mathrm{C}$. The result (Fig. 7) showed that the both states at $55^{\circ} \mathrm{C}$ and $45^{\circ} \mathrm{C}$ were retained up to $93^{\circ} \mathrm{C}$, i.e. the temperature required for melting of the final gel. Such a hysteresis does not seem to be compatible with a spinodal decomposition, but rather seems to result from an irreversible molecular association. This phenomenon might be caused by a zipper-like mechanism, in which the lateral association of molecules/helices develops after the random association of segments reaches a certain size. This can be viewed as a nucleation-related process.

Our present observation is expected to give clues to deeper understanding and better controls of the structure of the final gel. It is also of interest to investigate other gelling systems for possibility of similar phenomena when gelation is effected very slowly.

\section{Acknowledgements}

We thank Professor M. Shibayama, The University of Tokyo, for the use of UBM rheometer.

\section{References}

1. C. Araki, S. Hirase, Bull.Chem. Soc. Jpn., 6, 463 (1953)

2. S. Arnott, A. Fulmer, W. E. Scott, I. C. Dea, M. R. Moorhouse, D. A. Rees, J.Mol. Biol., 90, 269 (1974) .

3. S. A. Foord, E. D. T. Atkins, Biopolymers, 28, 1345 (1989).

4. I. C. M. Dea, A. A McKinnon, D. A. Rees, J. Mol. Biol. , 68, 153 (1972).

5. M. Djabourov, A. H. Clark, D. W. Rowlands, S. B. Ross-Murphy, Macromolecules, 22, 180 (1989).
6. C. Rochas, M. Lahaye, Carbohydr. Polym., 10, 289 (1989).

7. J. Jimenez-Barbero, C. Bouffar- Roupe, C. Rochas, S. Pérez, Int. J. Biol. Macromol., 11, 265 (1989).

8. M. Kouwijzer, S. Perez, Biopolymers, 46, 11 (1998).

9. J. N. Liang, E. S. Stevens, E. R. Morris, D. A. Rees, Biopolymers, 18, 327 (1979).

10. I. T. Norton, D. M. Goodall, K. R. J. Austen, E. R. Morris, Biopolymers, 25, 1009 (1986).

11. D.A. Rees, Advan. Carbohyd. Chem. Biochem, 24, 267 (1969).

12. J. M. Guenet, A. Brulet, C. Rochas, Int $J$ Bio Macromol, 15, 131 (1993).

13. J. Sugiyama., C.Rochas, T. Turquois, F. Taravel, H. Chanzy, Carbohydr. Polym. 23, 261 (1994).

14. M. Watase, K. Nishinari, A.H. Clark, S.B. Ross-Murphy, Macromolecules, 22,1196 (1989).

15. G.T. Feke, W. Prins, Macromolecules, 7, 527 (1974).

16. R. Letherby, D. Young, Chem Soc Faraday Trans, 77, 1953 (1981).

17. A. Emanuele, L. Distefano, D. Giacomazza, M.. Trapanese, M. B. Palma-Vitorelli, M. U. Palma, Biopolymers, 31, 859 (1991).

18. P. L. SanBiagio, D. Bulone, A. Emanuele, M. B. Vitorelli-Palma, M. U. Palma, Food Hydrocolloids, 10, 91 (1996).

19. M. Matsuo, T. Tanaka, L. Ma, Polymer, 43, 5299 (2002).

20. P. Aymard, D. R. Martin, K. Plucknett, T. J. Foster, A.H. Clark, I.T. Norton, Biopolymers, 59, 131 (2001).

21. K.C. Labropoulos, D.E. Niesz, S.C. Danforth, D.G. Kevrekidis, Carbohydr polym., 50, 407 (2002).

22. Z. H. Mohammed, M. W. N. Hember, R. K Richardson, E. R. Morris, Carbohydr. Polym.,36,15 (1998).

23. B.H. Zimm, J. Chem. Phys, 16, 105 (1948).

24. P. N. Pusey, W. van Megen, Physica A, 157, 705 (1989).

25. M. Shibayama, M. Tsujimoto, F. Ikkai, Macromolecules, 33,7868 (2000).

26. H. H. Winter, F. Chambon, J. Rheol., 30,367 (1986).

27. W. Burchard, S.B. Ross- Murphy, Physical Networks Polymers and Gels, Elsevier Appl. Sci.,NY, (1990).

28. P. G. De Gennes, Scaling concept in polymer physics. Ithaca, NY:Cornell University Press, (1979). 